\title{
Are You Being Rhetorical? A Description of Rhetorical Move Annotation Tools and Open Corpus of Sample Machine-Annotated Rhetorical Moves
}

\author{
Simon Knight ${ }^{1}$, Sophie Abel ${ }^{2}$, Antonette Shibani ${ }^{3}$, Yoong Kuan Goh ${ }^{4}$, Rianne Conijn ${ }^{5}$, Andrew \\ Gibson $^{6}$, Sowmya Vajjala ${ }^{7}$, Elena Cotos $^{8}$, Ágnes Sándor ${ }^{9}$, Simon Buckingham Shum ${ }^{10}$
}

\begin{abstract}
Writing analytics has emerged as a sub-field of learning analytics, with applications including the provision of formative feedback to students in developing their writing capacities. Rhetorical markers in writing have become a key feature in this feedback, with a number of tools being developed across research and teaching contexts. However, there is no shared corpus of texts annotated by these tools, nor is it clear how the tool annotations compare. Thus, resources are scarce for comparing tools for both tool development and pedagogic purposes. In this paper, we conduct such a comparison and introduce a sample corpus of texts representative of the particular genres, a subset of which has been annotated using three rhetorical analysis tools (one of which has two versions). This paper aims to provide both a description of the tools and a shared dataset in order to support extensions of existing analyses and tool design in support of writing skill development. We intend the description of these tools, which share a focus on rhetorical structures, alongside the corpus, to be a preliminary step to enable further research, with regard to both tool development and tool interaction.
\end{abstract}

\section{Keywords}

Writing analytics, corpus analysis, rhetorical moves, open data

Submitted: 31/10/19 — Accepted: 12/10/20 — Published: 17/12/20

Corresponding author ${ }^{1}$ Email: simon.knight@uts.edu.au Address: Faculty of Transdisciplinary Innovation, University of Technology Sydney, PO BOX 123, Broadway, NSW 2007, Australia, ORCID ID: https://orcid.org/0000-0002-8709-5780

2Email: sophie.abel@student.uts.edu.au Address: Connected Intelligence Centre, University of Technology Sydney, PO BOX 123, Broadway, NSW 2007, Australia, ORCID ID: https://orcid.org/0000-0001-5992-1910

${ }^{3}$ Email: antonette.shibani@uts.edu.au Address: Faculty of Transdisciplinary Innovation, University of Technology Sydney, PO BOX 123, Broadway, NSW 2007, Australia, ORCID ID: https://orcid.org/0000-0003-4619-8684

${ }^{4}$ Email: yoongkuan.goh@alumni.uts.edu.au Address: Connected Intelligence Centre, University of Technology Sydney, PO BOX 123, Broadway, NSW 2007, Australia, ORCID ID: https://orcid.org/0000-0002-8944-0410

${ }^{5}$ Email: m.a.conijn@tilburguniversity.edu Address: Department of Cognitive Science and Artificial Intelligence, Tilburg University, Tilburg, The Netherlands, ORCID ID: https://orcid.org/0000-0002-6316-4892

${ }^{6}$ Email: andrew.gibson@qut.edu.au Address: Science and Engineering Faculty, Queensland University of Technology, Brisbane, QLD, Australia, ORCID ID: https://orcid.org/0000-0003-4619-6515

7Email: sowmya.vajiala@nrc-cnrc.gc.ca Address: National Research Council, 1200 Montreal Road, Ottawa, Ontario, K1K 2E1, Canada, ORCID ID: https://orcid.org/0000-0002-4033-9936

${ }^{8}$ Email: ecotos@iastate.edu Address: lowa State University, 505 Morrill Rd., Ames, lowa, USA, ORCID ID: https://orcid.org/0000-0002-25159857

${ }^{9}$ Email: agnes.sandor@naverlabs.com Address: Naver Labs, 6 Chemin de Maupertuis, 38240 Meylan, France

${ }^{10}$ Email: simon.buckinghamshum@uts.edu.au Address: Connected Intelligence Centre, University of Technology Sydney, PO BOX 123, Broadway, NSW 2007, Australia, ORCID ID: https://orcid.org/0000-0002-6334-7429

\section{Introduction}

\subsection{Writing: A Core Educational Aim}

The importance of writing as a key professional skill is well established, yet, despite this importance, concern about students' writing capacity is long-standing (National Commission on Writing, 2003). Much of the support provided to students is targeted at academic English for non-native speakers or ad hoc remedial support (Wingate, 2012). As a result, the potential of learning analytics to provide formative feedback to students to support their writing is a growing area of interest (see, e.g., the following series of LAK workshops: Buckingham Shum, Knight, et al., 2016; Knight, Allen, Gibson, McNamara, \& Buckingham Shum, 2017; Shibani, Abel, Gibson, \& Knight, 2018). The writing feedback tools build on a longer history of automated essay scoring systems, which score constructed responses in standardized assessments, and automated writing evaluation systems, which provide instructional formative feedback, typically through targeted lessons on identified writing features (Warschauer \& Grimes, 2008). Tools that target specific levels of writing, such as middle/high school essays 
(e.g., Criterion-Burstein, Chodorow, \& Leacock, 2003), versus broader kinds of writing, such as emails and resumes (e.g., Grammarly: https://www.grammarly.com/), exist, many of which are covered in earlier reviews of computerized writing support (e.g., Allen, Jacovina, \& McNamara, 2016; McDonald, Moskal, Gunn, \& Donald, 2018; Shermis \& Burstein, 2013; Yan, Rupp, \& Foltz, 2020).

A feature that has been of particular interest in university-level writing is the rhetorical composition or structure ${ }^{1}$ of academic texts. This focus is premised on research demonstrating that expert writers express their ideas and arguments in a way that meets the reader's needs and makes clear the writer's rhetorical intent (Flower \& Hayes, 1977; Scardamalia \& Bereiter, 1987). A body of research has analyzed writing as socially situated and purposeful (Hyland, 2007; Swales, 1990) and has elaborated the view that the genre of a text emerges from shared communicative purposes and discourse conventions (termed moves by Swales (1981)), including organization and lexico-grammatical choices. This genre approach considers rhetorical structures as a means of "being explicit about the way language works to make meaning" (Cope \& Kalantzis, 1993, p. 1). Rhetorical moves allow writers to mobilize language to purposefully communicate with target discourse communities (such as the academic community) (Swales, 1990), expert members of which conform to the representational resources of genres by using moves as vehicles that help create clarity in communication.

The genre approach has been widely used to analyze texts and identify shared characteristic structural and linguistic patterns within the same genre, enabling explicit descriptions of writing conventions established and practised by discourse communities. Rhetorical moves are typically identified through particular patterns in textual units, such as sentences and sequences of sentences where language choices and metadiscourse explicitly contribute to the author's overall argument (Hyland, 2007; Swales, 1990). Perhaps the best-known formalization of the genre approach in the academic context is Swales's (Swales, 1981, 1990) Create a Research Space (CARS) model describing the rhetorical structures of research article introductions. By analyzing articles across multiple disciplines, Swales (1990) identified three rhetorical moves in introductions, which follow distinct patterns and a series of functional strategies within each move, called "steps":

1. establishing a research territory (including, e.g., the step "reviewing previous research"),

2. identifying a niche (including, e.g., the step "highlighting a problem or a gap in the existing knowledge"), and

3. occupying the niche (including, e.g., the step "presenting the contribution of the article itself in addressing that niche").

Appropriate language use is particularly important to accomplishing these steps and moves. For example, the phrase "Prior work has not yet established..." serves to highlight a gap, and "In this paper we describe..." introduces the present research.

The CARS model forms, more or less explicitly, the basis of much writing instruction in graduate research programs and has been extensively researched and validated across a variety of contexts (see discussion in Cotos (2018)). For example, it has been deployed to help graduate students identify rhetorical features in article introductions from their own disciplines (Cai, 2016; Cotos, Link, \& Huffman, 2017; Kuteeva \& Negretti, 2016). Although extensive research, particularly in the field of English for Specific Purposes within Applied Linguistics, yielded move models of the rhetorical conventions of different genres in different disciplines ${ }^{2}$, few tools have been developed for the automated analysis of these moves. Some of these tools (e.g., Anthony \& Lashkia, 2003; Chang \& Kuo, 2011; Cotos, 2011, 2014; Mizumoto, Hamatani, \& Imao, 2017) use genre analysis for teaching and providing automated feedback regarding the moves. Each tool was developed using different techniques and grounded in different datasets (and approaches to that data) or forms of validation, but no work has addressed the comparison of the functions and annotations of the tools, particularly using large open corpora. Thus, resources are scarce for comparing tools for both tool development and pedagogic purposes (e.g., using shared corpora to exemplify particular moves to students in teaching exercises).

In this paper, we describe a set of tools for rhetorical moves analysis and provide a preliminary corpus to aid in comparing the application of these to texts representative of scholarly academic writing. We intend this corpus to be a preliminary step to support further research, with regard to both tool development and interaction, that is, how students and educators engage with exemplifications of moves drawn from authentic open-access scholarly works. Two of the tools we use in this study are available openly, while one is not. This paper is intended to provide both a description of the tools and a shared dataset in order to support extensions of existing analyses and tool development in support of writing skill development.

\subsection{Writing Analytic Tools for Rhetorical Moves}

As noted above, among the various features that can be identified in student writing, rhetorical structures are particularly

\footnotetext{
${ }^{1}$ The identity between our term rhetorical structure and the rhetorical structure theory (RST) of Mann and Thompson (1987) is misleading. In RST, rhetorical structure refers to temporal, causal, and so on, discourse relations between elementary discourse units, whereas in the tools we present it refers to higher-level genre-specific communicative strategies.

${ }^{2}$ Numerous research studies have been conducted over decades to validate the move analysis approach in general and the CARS model in particular, but reviewing them is beyond the scope of this article. Interested readers are referred the Journal of English for Academic Purposes and the English for Specific Purposes journals.
}

ISSN 1929-7750 (online). The Journal of Learning Analytics works under a Creative Commons License, Attribution - NonCommercial-NoDerivs 3.0 Unported (CC BY-NC-ND 3.0) 
important, and they have received considerable attention in the teaching and research of writing for academic purposes. As a result of this, several tools have been developed to automatically identify these structures in academic writing and annotate their presence in a text. These tools and their background will be briefly introduced in this section, while the next section discusses the corpus to which the tools have been applied. These tools are (1) Mover, (2) Research Writing Tutor, and (3) Academic Writing Analytics (AWA) and AcaWriter tools, the background to which is introduced in general first, and then for the two versions of the tool individually ${ }^{3}$.

\subsubsection{Mover}

Background: The Mover tool (Anthony \& Lashkia, 2003) was developed to identify the structure of information technology research article abstracts. Mover analyzes text based on a version of Swales's (1990) CARS framework modified by Anthony (1999).

Purpose and Evaluation: Mover was developed to help novice readers and writers understand the rhetorical organization of a text. The tool's practicality was tested with students in two experiments (Anthony \& Lashkia, 2003). The first experiment focused on six students, who were asked to read 10 abstracts and comment on the structure according to the modified CARS moves. The experiment was then repeated with a different set of abstracts; however, this time students used Mover to help them read the text. The authors found that when students were asked to comment on the abstracts without the help of Mover, only one of the five could do so, and they took over an hour on the task. However, when students did the same task with Mover, they were all able to identify moves, their frequency, and the structure of the abstracts, in an average of 15 minutes. The second experiment (Anthony \& Lashkia, 2003) focused on the usefulness of Mover in the writing process. First, students were asked to evaluate their own draft abstract and revise it based on rhetorical structure. The experiment was then repeated, but this time students used Mover to help them evaluate their drafts. The authors found that students were able to evaluate and revise their drafts more quickly with the help of Mover.

Technical Implementation: The Mover system provides a front-end graphical user interface that applies a supervised machine learning model that was trained on 100 research abstracts in information technology to identify modified CARS moves in text input files. It provides as output a set of text files split into files organized by move type.

Resources: The tool is available as a Freeware download from http://www.laurenceanthony.net/software/antmover/ along with a help file for its use to annotate texts.

\subsubsection{Research Writing Tutor}

Background: Similarly to the Mover tool, the Research Writing Tutor (RWT) automatically identifies rhetorical structures in research articles. Unlike Mover, RWT analyzes all of the sections of the research article. Following Swales's (1990) move analysis approach and drawing on his CARS model, the researchers developed a comprehensive introduction-method-resultsdiscussion/conclusion (IMRD/C) move/step framework (see Figure 1 below from Cotos, Huffman, \& Link, 2015). This framework was then applied to the development of different technical affordances of the RWT (Cotos, 2016).

\begin{tabular}{|c|c|c|c|}
\hline Introduction & Methods & Results & Discussion/Conclusion \\
\hline $\begin{array}{l}\text { Move 1: Establishing the territory } \\
\text { Step 1 - Claiming centrality } \\
\text { Step 2 - Providing general background } \\
\text { Step 3 - Reviewing previous research } \\
\text { Move 2: Identifying a niche } \\
\text { Step 1 - Indicating a gap } \\
\text { Step 2 - Highlighting a problem } \\
\text { Step 3 - Raising general questions } \\
\text { Step 4 - Proposing general hypotheses } \\
\text { Step 5 - Presenting justification } \\
\text { Move 3: Addressing the niche } \\
\text { Step 1 - Introducing present research } \\
\text { descriptively } \\
\text { Step 2 - Announcing present research } \\
\text { purposefully } \\
\text { Step 3 - Presenting research questions } \\
\text { Step 4-Presenting research hypotheses } \\
\text { Step 5 - Clarifying definitions } \\
\text { Step 6- Summarizing methods } \\
\text { Step 7-Announcing principle outcomes } \\
\text { Step 8- Stating the value of present } \\
\text { research } \\
\text { Step 9-Outlining the structure of the } \\
\text { paper }\end{array}$ & $\begin{array}{l}\text { Move 1: Contextualizing the study } \\
\text { methods } \\
\text { Step 1 - Referencing previous works } \\
\text { Step 2 - Providing general information } \\
\text { Step 3 - Identifying the methodological } \\
\text { approach } \\
\text { Step 4 - Describing the setting } \\
\text { Step 5 - Introducing the } \\
\text { subjects/participants } \\
\text { Step 6 - Rationalizing pre-experiment } \\
\text { decisions } \\
\text { Move 2: Describing the study } \\
\text { Step 1 - Acquiring the data } \\
\text { Step 2 - Describing the data } \\
\text { Step 3 - Identifying variables } \\
\text { Step 4 - Delineating } \\
\text { experimental/study procedures } \\
\text { Step 5 - Describing } \\
\text { tools/instruments/materials/equipment } \\
\text { Step 6- Rationalizing experiment } \\
\text { decisions } \\
\text { Step } 7 \text { - Reporting incrementals } \\
\text { Move 3: Establishing credibility } \\
\text { Step 1 - Preparing the data } \\
\text { Step 2 - Describing the data analysis } \\
\text { Step 3 - Rationalizing data } \\
\text { processing/analysis }\end{array}$ & $\begin{array}{l}\text { Move 1: Approaching the niche } \\
\text { Step 1 - Providing general orientation } \\
\text { Step 2 - Restating study specifics } \\
\text { Step 3 - Justifying study specifics } \\
\text { Move 2: Occupying the niche } \\
\text { Step 1 - Reporting specific results } \\
\text { Step 2 - Indicating altemative } \\
\text { presentation of results } \\
\text { Move 3: Construing the niche } \\
\text { Step 1 - Comparing results } \\
\text { Step 2 - Accounting for results } \\
\text { Step 3 - Explicating results } \\
\text { Step 4 - Clarifying expectations } \\
\text { Step 5 - Acknowledging limitations } \\
\text { Move 4: Expanding the niche } \\
\text { Step 1 - Generalizing results } \\
\text { Step 2 - Claiming the value } \\
\text { Step 3 - Noting implications } \\
\text { Step 4 - Proposing directions }\end{array}$ & $\begin{array}{l}\text { Move 1: Re -establishing the } \\
\text { territory } \\
\text { Step 1 - Drawing on /theoretical } \\
\text { general background } \\
\text { Step 2 - Drawing on study-specific } \\
\text { background } \\
\text { Step 3 - Highlighting principal } \\
\text { findings } \\
\text { Step 4 - Previewing the discussion } \\
\text { 'road map' } \\
\text { Move 2: Framing the new } \\
\text { knowledge } \\
\text { Step 1 - Explicating results } \\
\text { Step 2 - Accounting for results } \\
\text { Step 3 - Clarifying expectations } \\
\text { Step 4 - Addressing limitations } \\
\text { Move 3: Reshaping the territory } \\
\text { Step 1 - Supporting with evidence } \\
\text { Step 2 - Countering with evidence } \\
\text { Move 4: Establishing additional } \\
\text { territory } \\
\text { Step 1 - Generalizing results } \\
\text { Step 2 Claiming the value } \\
\text { Step 3 - Noting implications } \\
\text { Step 4 - Proposing directions }\end{array}$ \\
\hline
\end{tabular}

Figure 1. IMRD/C move/step framework operationalized in RWT

\footnotetext{
${ }^{3}$ We are also aware of SAPIENTA (Liakata, Saha, Dobnik, Batchelor, \& Rebholz-Schuhmann, 2012), which is based on the Argumentative Zoning scheme (Teufel \& Moens, 2002). SAPIENTA has the potential to assist research students with their research writing, but it is currently not used in a pedagogical context. Instead, SAPIENTA has been used to extract summaries of articles to provide a more detailed summary than an abstract (Liakata et al., 2012).
}

ISSN 1929-7750 (online). The Journal of Learning Analytics works under a Creative Commons License, Attribution - NonCommercial-NoDerivs 3.0 Unported (CC BY-NC-ND 3.0) 
Purpose and Evaluation: RWT was designed to complement advanced academic writing instruction and to provide genrebased feedback on students' IMRD/C drafts. It contains three modules: a learning module called Understand Writing Goals, a demonstration module called Explore Published Writing, and a feedback module called Analyze My Writing.

The learning module aims to help students understand their discipline's research writing conventions. The learning materials used in this module draw from the results of large-scale studies (Cotos et al., 2015; Cotos, Link, \& Huffman, 2016; Cotos, Huffman, \& Link, 2017) in which 900 research articles from 30 disciplines were analyzed to develop a move/step framework for each section of research articles that follow the IMRD/C structure. This module explains the moves and their respective steps and provides representative examples from the corpus. It also includes language focus materials that describe patterns of language use characteristic of each move. Short video lectures cover this move-specific content (see Figure 2).

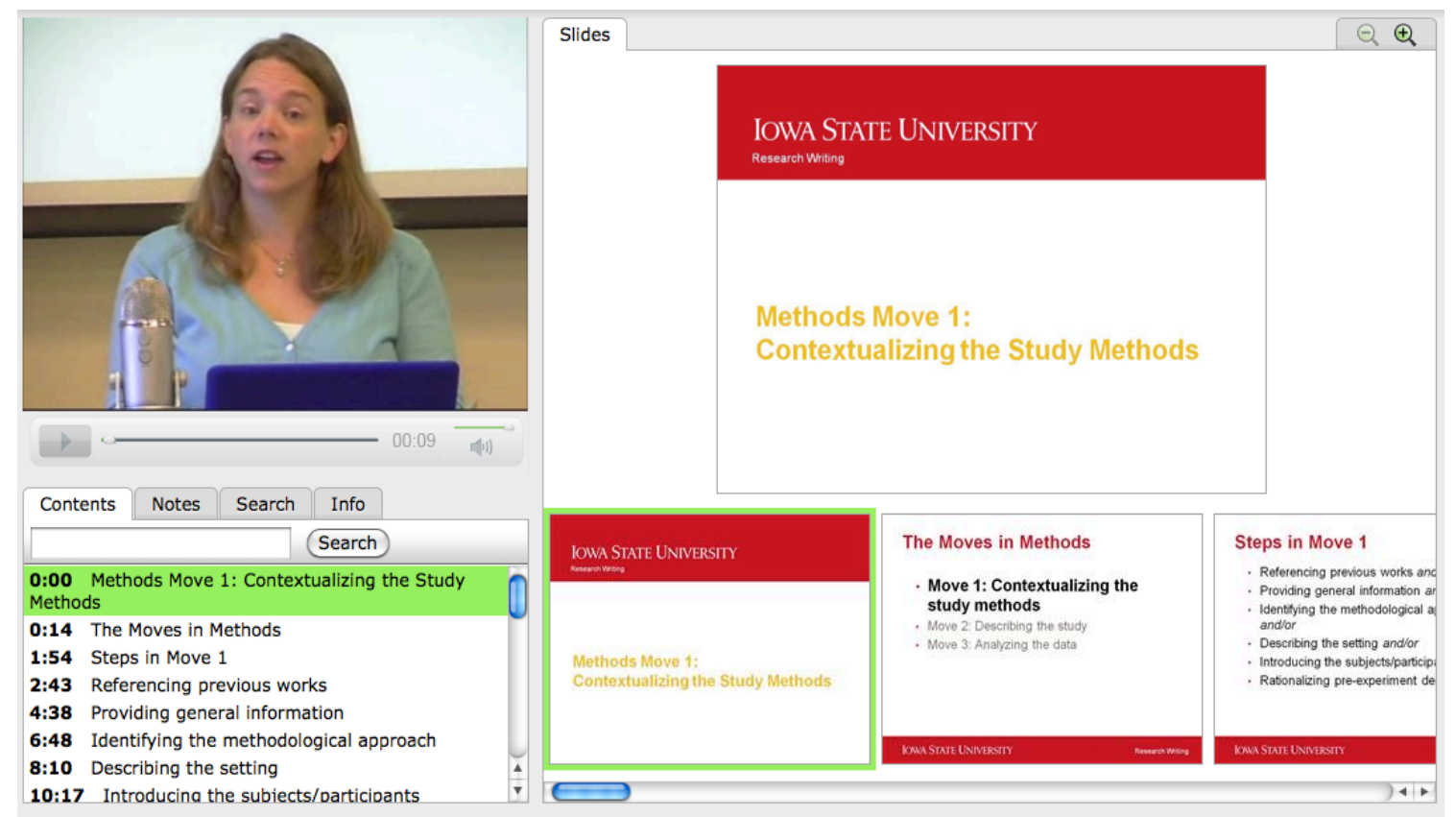

Figure 2. Screenshot exemplifying the video presentation of move-specific content in the learning module of RWT

The demonstration module intends to expose students to the move/step conventions of each IMRD/C section, as used by expert writers, by integrating the corpus mentioned above into interrelated components. In one component, IMRD/C texts are shown with move and step annotations at sentence level. The IMRD/C moves are consistently represented with the same colours: Move 1 is blue, Move 2 is red, Move 3 is green, and Move 4 is gold (see Figure 3).

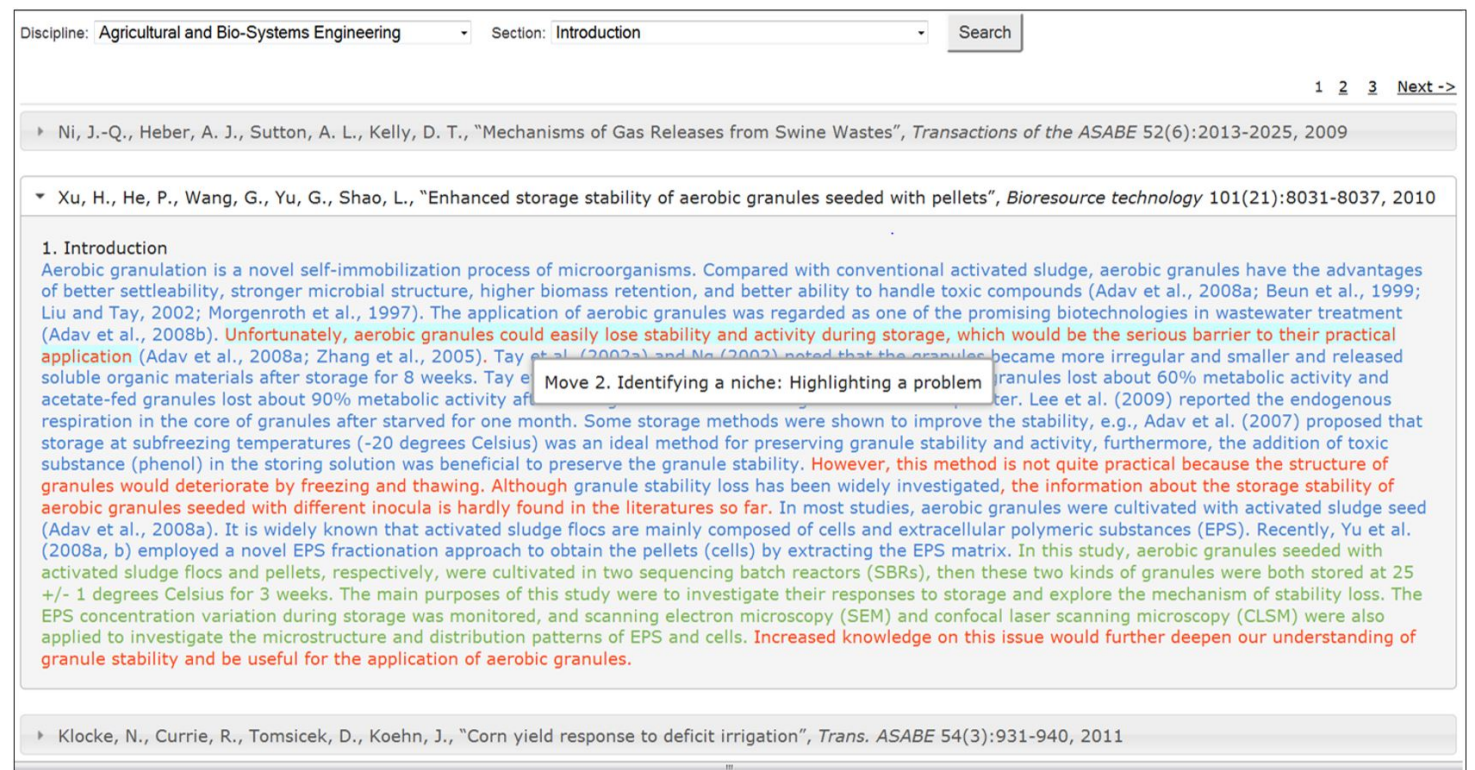

Figure 3. Screenshot exemplifying an annotated introduction text in the demonstration module of RWT

ISSN 1929-7750 (online). The Journal of Learning Analytics works under a Creative Commons License, Attribution - NonCommercial-NoDerivs 3.0 Unported (CC BY-NC-ND 3.0) 
Another component contains a concordancer that allows students to search for examples by filtering for discipline, section, move, and step (see Figure 4).

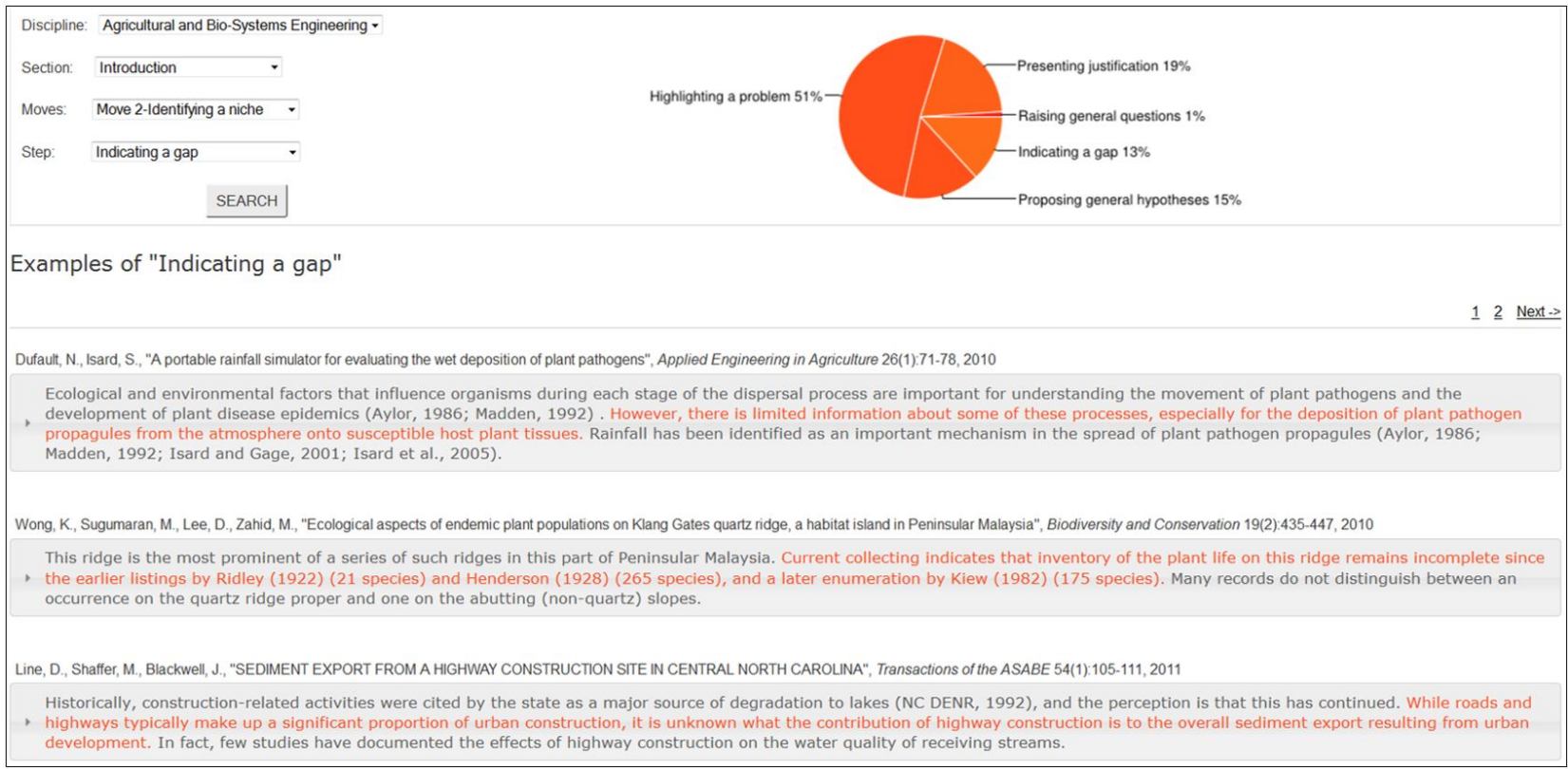

Figure 4. Screenshot exemplifying step examples in the concordancer of the demonstration module of RWT

The feedback module generates automated feedback on student drafts at macro and micro levels. The macro-level feedback renders the move structure of the draft through colour codes (as in the demonstration module) and through range bars and pie charts, which quantitatively describe the move distribution of the draft compared with published texts in the target discipline. The micro-level feedback focuses on the text's steps and provides comments and questions that clarify the rhetorical intent of that sentence. This type of feedback appears when students hover over each sentence. Figure 5 exemplifies these forms of feedback with respective screenshots.
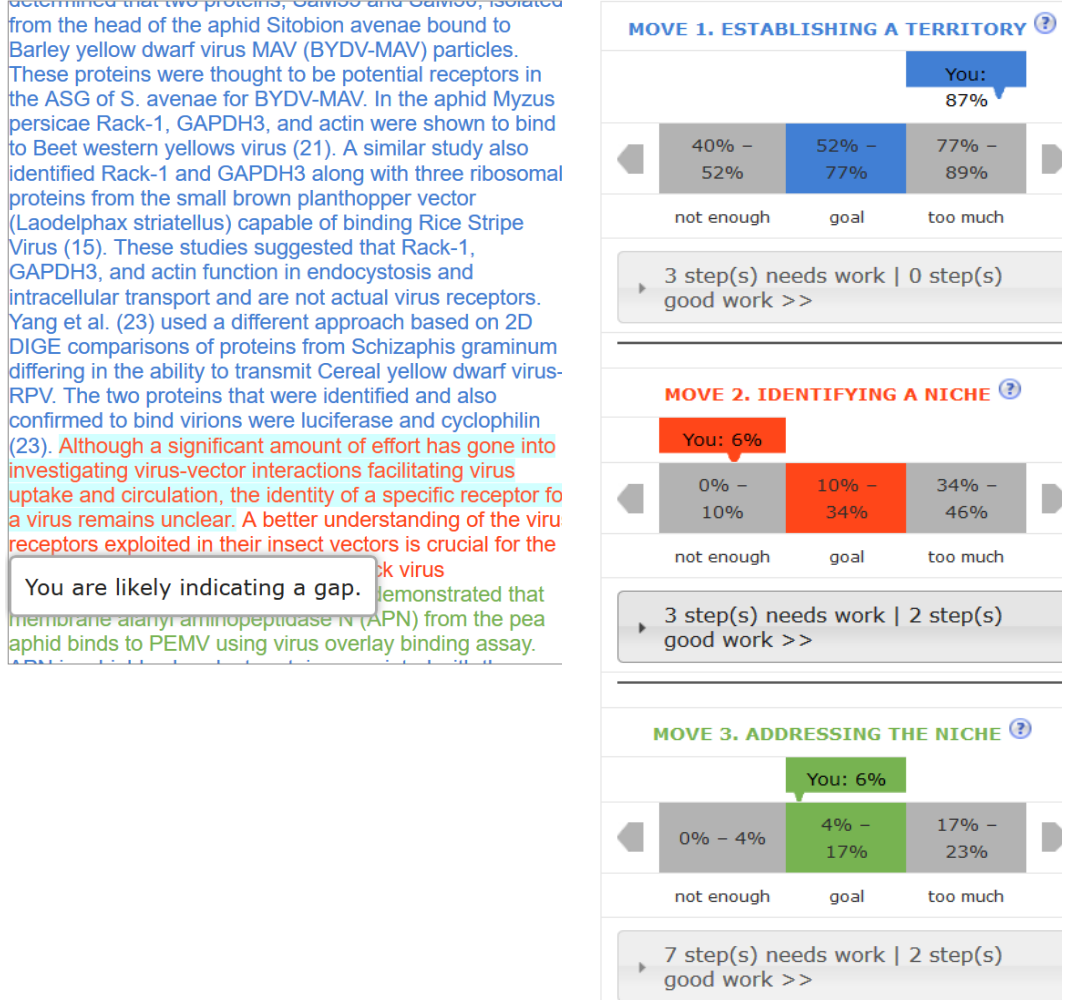

3 step(s) needs work | 2 step(s) good work $>>$

(9) Good work on indicating a gap. Very similar to Microbiology papers. Learn More I Examples

! Lacking highlighting a problem, which is typically used in Microbiology papers. Needs more work. Learn More I Examples

I Lacking proposing general hypotheses, which is typically used in Microbiology papers. Needs more work. Learn More I Examples

(9) Good work on presenting justification. Very similar to Microbiology papers. Learn More I Examples

! Lacking raising general questions, which is typically used in Microbiology papers. Needs more work. Learn More I Examples

Figure 5. Screenshots exemplifying different forms of feedback in the feedback module of RWT 
A number of studies on usefulness and effectiveness have been conducted to inform RWT's iterative development and explore how RWT impacts students and their research writing. Empirical evidence indicates that students' interaction with this tool has a positive impact on cognition, revision strategies, learning of genre conventions, development of genre knowledge, writing improvement, and motivation (Cotos, 2016; Cotos, Huffman, \& Link, 2020; Cotos et al., 2017). While RWT was initially designed to complement graduate writing pedagogy, it has been used in different learning environments, such as peer writing groups, one-on-one consultations with writing tutors, and graduate writing workshops.

Technical Implementation: The researchers applied their IMRD/C move/step framework shown in Figure 1 to manually annotate their large multi-disciplinary corpus of research articles and used a machine learning approach (support vectors) to automatically classify sentences into moves and steps (Cotos \& Pendar, 2016). New sentences are classified with a probability distribution, rendered to the user as the different types of feedback described above. In the work described in this paper, this approach was re-implemented in Python using logistic regression.

Resources: A demo of the RWT tool is available at https://vimeo.com/90669213. The tool is currently not accessible outside of individual institutions but can be given access to upon request and agreement to institutional terms. The annotated corpus on which the tool was trained is copyrighted and thus also not publicly available.

\subsubsection{Academic Writing Analytics and AcaWriter}

Background: The Academic Writing Analytics (AWA) tool and its successor AcaWriter are two feedback systems based on a rhetorical analysis framework called concept-matching (Sándor, 2007) and its implementation in the Xerox Incremental Parser (XIP) (Ait-Mokhtar, Chanod, \& Roux, 2002) and in the open-source Athanor tool (https://github.com/uts-cic/athanorserver), respectively. AWA and AcaWriter have two modules: one that provides feedback on analytical student essays (see Knight et al., 2017) and one that provides feedback on reflective student essays (see Gibson et al., 2017; Buckingham Shum, Sándor, et al., 2016). In this paper, we focus on the analytical module. AWA and AcaWriter have been developed along the same line of research, with AcaWriter bringing in a new open-source infrastructure and pedagogic implementation. In this section, we will first present their common background, and then we will briefly discuss them individually.

Both tools use a rule-based parser that labels rhetorically salient sentences (Sándor, 2007), meaning they convey particular rhetorical intent. Grounded in Hyland's and Swales's work, and in analyses of peer-reviewed research articles in a variety of fields, the parser distinguishes different types of rhetorical intent and labels them as follows: summarizing issues (describing the article's plan, goals, and conclusions) (S); describing background knowledge (B); contrasting ideas (C); emphasizing important ideas (E); mentioning novel ideas (N); pointing out surprising facts, results, and so on (S); describing an open question or insufficient knowledge (Q); and recognizing research trends $(\mathrm{T})$. These broadly correspond to a number of steps pertaining to the moves in Swales's model, like claiming centrality, indicating a gap, and so on; therefore, we will henceforth refer to them as steps. AWA's user interface refers collectively to these sentence types as important sentences. Unlike Mover and RWT, AWA and AcaWriter do not annotate all of the sentences.

Technical Implementation and Evaluation: The rules implemented in both tools are based on an updated version of the rhetorical parsing module (Sándor, 2007) of XIP. They match expressions conveying the rhetorical steps listed above based on the detection of the instantiations of syntactically related "constituent concepts" (c.f. the "concept-matching" framework (Sándor, Kaplan, \& Rondeau, 2006)). Thus, for example, as outlined in Knight, Buckingham Shum, Ryan, Sándor, and Wang (2018), "contrast" sentences include syntactically related words that instantiate the concept of both "idea" and "contrast."

"Thus the following 3 syntactically and semantically different sentences are all labeled ' $\mathrm{C}$ ' by AWA, since the words in bold match this pattern: challenge, need, failure, and shift convey 'contrast' and identify, highlights, demonstrating, and notions convey 'idea/mental operation.' The two classes of words are syntactically related in all three sentences:

C The second challenge is to identify different types of SLA and their associated technologies and uses.

C Consequently this highlights the essential need for repair.

C Finally demonstrating various solutions and the pragmatic failure or success of these with close regard to case law as

well as the notions expressed by Keane in particular a shift of current ideology surrounding discovery."

(Knight et al., 2018, p. 5)

Prior work using the XIP rhetorical parser indicated that the detection of the rhetorical steps mentioned above could be used to identify "paradigm shifts" in biomedical research abstracts (Lisacek, Chichester, Kaplan, \& Sándor, 2005), and that it could effectively support peer reviewers (Sándor \& Vorndran, 2009) and project evaluators (De Liddo, Sándor, \& Buckingham Shum, 2012) in navigating the research they were reviewing. In addition, Simsek et al. (2015) suggested that the presence of these steps had some correlation with undergraduate essay quality. This evidence established the potential of the XIP rhetorical parser for annotating rhetorical steps in academic writing and led to its application in the AWA tool as a hosted service.

\subsubsection{AWA and XIP}

Background: From 2015 to 2017, work was undertaken to apply the rhetorical parser, based on XIP, to create a student-facing

ISSN 1929-7750 (online). The Journal of Learning Analytics works under a Creative Commons License, Attribution - NonCommercial-NoDerivs 3.0 Unported (CC BY-NC-ND 3.0) 
writing analytics tool in order to provide support for academic writing.

Purpose and Evaluation: The initial AWA tool was developed as part of a collaboration with the Xerox Research Centre Europe (XRCE), now under new ownership as Naver Labs Europe. As described in detail in Knight et al. (2018), it provided feedback by highlighting rhetorical steps in student writing in order to encourage students to reflect on these steps (and their absence) and revise their text. Evaluation in the context of legal education (Knight et al., 2018) indicated that the highlighted steps were perceived as important in undergraduate academic writing and that students valued the potential of the tool. A later study made use of this feedback on rhetorical steps from XIP and AWA to integrate it into a larger pedagogical task involving writing activities and instruction (Shibani, Knight, Buckingham Shum, \& Ryan, 2017). Until this stage, AWA feedback consisted of highlighting rhetorical steps in the text but provided no additional feedback messages on what to improve. Students generally found this writing intervention useful to improve their writing and expressed a preference for more actionable feedback in their context of writing. However, students used the tool only in a single session after submitting their assignment, and no longer-term studies were conducted, nor was impact on the quality of writing assessed. Figure 6 shows a sample interface of AWA with rhetorical steps highlighted as feedback.

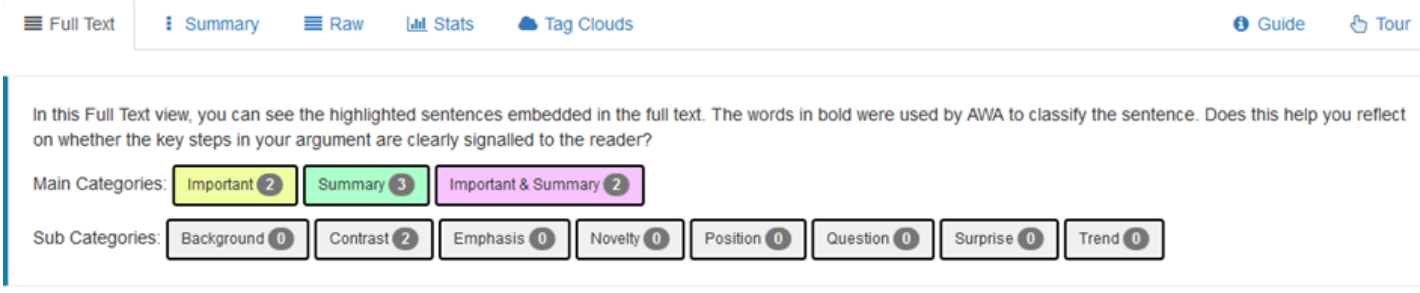

Information seeking and processing are key literacy practices. However, they are activities that students, across a range of ages, struggle with. These information seeking processes can be viewed through the lens of epistemic cognition: beliefs regarding the source, justification, complexity, and certainty of knowledge. Research in this area has typically used self-report psychometric and behavior data, and information seeking tasks involving closed-document sets. The research described in this paper applies established self-report measures to a large-scale, naturalistic, study environment. The novel approach taken in the paper points to the potential of analysis of dialogue, web-navigation - including sites visited - and other trace data, to support more traditional self-report mechanisms. Contrast Analysis of self-report data indicates that, although relationships can be observed between self-report indicators, hypothesized relationships between self-report and trace-indicators are not supported. Contrast The article thus points to the need for further investigation of behavioural learning analytic data in understanding how epistemic cognition is brought to bear in rich information seeking and processing tasks.

Information seeking and processing are key literacy practices. However, they are activities that students, across a range of ages, struggle with. These information seeking processes can be viewed through the lens of epistemic cognition: beliefs regarding the source, justification, complexity, and certainty of knowledge. In the research reported in this article we build on established research in this area, which has typically used sell-report psychometric and behavior data, and information seeking tasks involving closed-document sets. We take a novel approach in applying established self-report measures to a large-scale, naturalistic, study environment, pointing to the potential of analysis of dialogue, web-navigation - including sites visited - and other trace data, to support more traditional self-report mechanisms. Our analysis suggests that prior work demonstrating relationships between self-report indicators is not paralleled in investigation of the hypothesized relationships between self-report and trace-indicators. However, there are clear epistemic features of this trace data. The article thus demonstrates the potential of behavioural learning analytic data in understanding how epistemic cognition is brought to bear in rich information seeking and processing tasks.

Kingdom, Australia has remained stagnant in its development of thild party liability for knowing assistance. This paper
seeks to argue that the High Court's preferential use of precedents over legal and equitable principles has hindered the
coded according to their broad type
development of third party liability in the knowing assistance of trust or fiduciary duties. This over-refinement of the two

\begin{tabular}{l} 
Summary \\
Important \\
Both \\
B Background \\
C) Contrast \\
(E) Emphasis \\
(N) Novelty \\
(P) Position \\
Q Q Question \\
\hline S Surprise \\
\hline T) Trend
\end{tabular}

\begin{abstract}
fiduciaries such as lawyers cannot. Ac assists a solicitor in a breach of fiduci which could ever apply to relieve the :

CONTRAST: Disagreement, tension, options, inconsistency

cessorial liability of a third party, which ct, or the Corporations Act; neither of

It appears that the plainly wrong finding in respect of Bell was based, primarily, on: CDrummond AJA's incorrect interpretation of the dishonest and fraudulent design requirement as articulated in Farah ; and the lack of careful formulation of the Bell Test, which fails to appreciate the inconsistent or unsound practical effect of imposing a test which is to be analogous to that imposed by other legislative provisions - despite those provisions operating in a separate and, in some ways, dissimilar context. The explication of the NSWCA's deter concerning Bell provides

\section{Sentences with Function Keys have} more precise functions (e.g. Novelty)
\end{abstract}

Figure 6. Sample AWA interfaces

Technical Implementation: The initial AWA was written in PHP, with a subsequent version (AWA 2) developed in Ruby, both making use of the rule-based XIP parser for detecting the presence of rhetorically salient features in student writing and highlighting these sentences to students. Students pasted their text, or copied their file, into the text box provided and then obtained the generated feedback. In the background, AWA made calls to XIP to process the text and displayed the output report using the json output returned by XIP.

Resources: AWA and XIP Incremental Parser are both now depreciated. 


\subsubsection{AcaWriter and TAP}

Background: AcaWriter and TAP (Text Analytics Pipeline) are open-source versions of AWA and XIP, respectively, with improved features. The new versions provide greater flexibility. The underlying technical infrastructure that processes text in TAP allows the integration of different text analytics and feedback options. The middleware layer and the user interface in AcaWriter also allow the development of customized feedback rules, in addition to the earlier sentence-level highlighting in AWA (see implementation).

Purpose and Evaluation: AcaWriter uses TAP to perform NLP processing, but the output needs to be converted to useful feedback for students in the form of reports and/or messages. AcaWriter carries out this middleware job by mapping the text features to feedback. In addition to the highlights of rhetorical steps in AWA for reflection, the recent version of AcaWriter also allows for customizable feedback for students on specific genres of writing (see Shibani, Knight, \& Buckingham Shum, 2019)

\begin{tabular}{|c|c|}
\hline Analytical Report & Analytical Report \\
\hline $\begin{array}{l}\text { The analytical report highlights salient rhetorical moves AcaWriter identified in your essay for reflection. For more } \\
\text { specific feedback, go to the Feedback tab. } \\
\text { Rhetorical Moves } \\
\text { S Summarises or signals the authors goals P Perspective or stance } \\
\text { E Emphasis to highlight key ideas N Novel improvements in ideas } \\
\text { C Contrasting idea, tension or critical insight } \\
\text { B Background information and previous work S Surprising or unexpected finding }\end{array}$ & $\begin{array}{l}\text { D The rhetorical moves highlighted by AcaWriter are used in good academic writing but use } \\
\text { them with caution according to the context. Remember, AcaWriter does not really understand your } \\
\text { writing, the way people do. You may have written beautifully crafted nonsense - that's for you to } \\
\text { decide! Moreover, writing is complex, and AcaWriter will get it wrong sometimes. If you think it got } \\
\text { it wrong, that's fine - now you're thinking about more than spelling, grammar, and plagiarism. }\end{array}$ \\
\hline $\begin{array}{l}\text { Introduction } \\
\text { Rapidly advancing technology has been seen as a marker of contemporary modernity. It ha } \\
\text { been a formidable vessel in transporting old world values and traditions into a new world of }\end{array}$ & $\begin{array}{l}\text { (- It looks like you are missing a Summary move that highlights the purpose (thesis) statement } \\
\text { of your essay and your essay plan. Try including linguistic cues to make this move clearer in your } \\
\text { writing. Examples: This essay talks about.., In this essay, I analyse.... This essay consists of three } \\
\text { parts... The first part talks about..., In conclusion.... }\end{array}$ \\
\hline $\begin{array}{l}\text { innovation and deviation. In the legal world, the growing area of cyber-crime, metadata and } \\
\text { privacy laws all affirm the idea that technological change is inescapable. CQ However, } \\
\text { little research has been conducted to assess the benefits and risks of these innovations as } \\
\text { they would apply to civil practice. } \mathbf{S} \\
\text { This essay will review the implementation of video conferencing technologies in courts. } \mathbf{N}\end{array}$ & $\begin{array}{l}\text { (1t looks like you are missing a Background move in your text, which highlights background } \\
\text { information and previous literature on the topic. Try including linguistic cues to make this move } \\
\text { clearer in your writing. Examples: The past decade has seen ..... Recent studies indicate ..., It is } \\
\text { generally accepted that..., the concept has previously been thought to be... }\end{array}$ \\
\hline 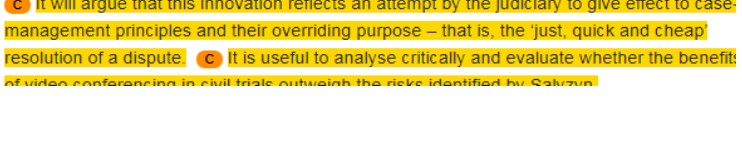 & $\begin{array}{l}\text { (It looks like you are missing contrast/Question move, which highlights the critical insights in } \\
\text { your essay. Try including linguistic cues to make this move clearer in your writing. Examples: } \\
\text { However, the issue seems to be..., the study fails to consider, little research has been done..., } \\
\text {...raises various questions... }\end{array}$ \\
\hline & $\begin{array}{l}\text { - If there is a key idea you did like to emphasises in your essay try including linguistic cues to } \\
\text { make this move clearer in your writing. Examples: It is important to note that ...., It makes a proper } \\
\text { understanding important... }\end{array}$ \\
\hline
\end{tabular}

\section{ETS AcaWriter * a $\quad$ My Dashboard Example Texts Manage Assignment $\quad$ Antonette Aileen Shibani Michael Xavier -}

AcaWriter works fastest with short texts, so if yoưre only working on a specific section, dont paste in the whole document. still processes long texts, but it may take a few minutes to get your feedback to you.

\section{B $I \cup \underline{i}=$}

Recent research concludes that technology is an enabler in providing greater access to justice through its ability to connect people with legal needs to legal assistance, information, and advice. With the increasing popularity of internet-enabled hand held devices and laptop computers, there is a tendency to assume that even the socio-economically vulnerable in our society have access to technology and the skills to use online services with confidence. This is not necessarily the case.

Examples of the application of technology to provide legal information and assistance include case studies, guides and virtual legal advice clinics. The 2012 Review does not address the role of courts in serving the legal needs of the community. The court system is not regarded as a part of the wider legal assistance services. This omission questions the role of the court in facilitating access to its services, including dispute resolution and trials. It also identified uses of technology to expand the delivery of services, many of which are transferable to an online court. These services include e-access for remote communities, availability outside of business hours, interactive processes and virtual appearances. This essay will discuss uses of technology to expand the delivery of services, many of which are transferable to an online court.
NOTE: Computers don't understand writing like humans. So, AcaWriter may highlight metorically good sentences that actually make no sense, or leave un-highlighted a sentence that you feel is really good. It's fine to disagree with the feedback - but it's also your job to check your facts!

\section{$\begin{array}{lll}\text { Analytical Report } & \text { Feedback } & \text { Examples }\end{array}$}

(1) The analytical report highlights salient rhetorical moves AcaWriter identified in your essay for reflection. For more specific feedback, go to the Feedback tab. Rhetorical Moves

$$
\begin{aligned}
& \text { S Summarises or signals the authors goals Perspective or stance } \\
& \text { E Emphasis to highlight key ideas N Novel improvements in ideas } \\
& \text { C Contrasting idea, tension or critical insight } \\
& \text { B Background information and previous work S Surprising or unexpected finding } \\
& \text { Q Question or gap in previous knowledge T Trend or tendency related to ideas }
\end{aligned}
$$

B Recent research concludes that technology is an enabler in providing greater access to justice through its ability to connect people with legal needs to legal assistance, information, and advice. $T$ With the increasing popularity of internet-enabled hand held devices and laptop computers, there is a tendency to assume that even the socio-economically vulnerable in our society have access to technology and the skills to use online services with confidence.

Figure 7. Sample analytical report in AcaWriter highlighting rhetorical moves in the writing. Top pane indicates the editor (left) and feedback (right); bottom pane shows the detailed feedback (left) and feedback messages (right) 
A number of studies on usefulness, effectiveness, and integration into pedagogic practice have been conducted that inform the design and implementation of the AcaWriter tool. These studies indicate that students find the tool useful, that it supports them in including more rhetorical expressions in their text, and that students who use the tool perform better on a revision task than those who do not (Knight, Shibani, et al., 2020; Shibani, 2018a, 2018b; Shibani et al., 2017). In addition, educator experiences of using the tool and transferring its use from one disciplinary context to another have been investigated, with the significance of learning design highlighted as a key issue in this process (Shibani, Knight, \& Buckingham Shum, 2020).

Technical Implementation: TAP provides a modular structure for developing and using natural language processing (NLP) technology in end-user applications via API calls. TAP is an open-source software that runs as a web application in the cloud and provides convenient GraphQ1 API access to a variety of text analytics processes. TAP delivers a number of natural language processing features using pre-built models and parsers, including detection of emotion and rhetorical steps through the REST-API Athanor-server, which instantiates the rhetorical rules through Stanford CoreNLP.

Resources: The Resources menu at http://heta.io/resources provides an overview of the different genres of writing that AcaWriter can support analysis of, along with descriptions of the learning designs for integrating the tool into classrooms. There is a test demo system, which provides some example texts and feedback genres, at http://acawriter-demo.utscic.edu.au. And, finally, the tool set has been released open source, including TAP, under an Apache 2.0 licence, and AcaWriter (the front end); see https://cic.uts.edu.au/open-source-writing-analytics and a sample notebook that demonstrates many of the functions of the toolset at https://github.com/uts-cic/ALASI2018-WritingAnalyticWorkshop.

\subsubsection{Comparison of Rule-Based and Machine Learning Approaches}

Each of these tools is based in genre theory, in the field of English for specific purposes, intended for different purposes and implemented differently, applying both machine learning and rule-based approaches, as summarized in Table 1.

Table 1. Overview Comparison of Tools

\begin{tabular}{|c|c|c|c|c|}
\hline & Mover & RWT & AWA/XIP & AcaWriter/TAP \\
\hline Purpose & $\begin{array}{l}\text { Support higher-degree learners } \\
\text { in identifying and learning } \\
\text { moves through their } \\
\text { exploration across science- and } \\
\text { engineering-related fields }\end{array}$ & $\begin{array}{l}\text { Support higher-degree } \\
\text { research (HDR)/graduate } \\
\text { student writing }\end{array}$ & $\begin{array}{l}\text { Support primarily } \\
\text { undergraduate } \\
\text { writing }\end{array}$ & $\begin{array}{l}\text { Support } \\
\text { academic } \\
\text { writing across } \\
\text { levels }\end{array}$ \\
\hline Implementation & $\begin{array}{l}\text { Machine learning (naive Bayes } \\
\text { classifier) based on annotated } \\
\text { corpus of } 100 \text { information } \\
\text { technology research article } \\
\text { abstracts }\end{array}$ & $\begin{array}{l}\text { Machine learning (suite of } \\
\text { support vector machine } \\
\text { classifiers for moves and } \\
\text { steps) trained on a corpus } \\
\text { of } 900 \text { research articles } \\
\text { from } 30 \text { disciplines } \\
\text { manually annotated for } \\
\text { moves and steps }\end{array}$ & $\begin{array}{l}\text { Rule-based } \\
\text { approach }\end{array}$ & $\begin{array}{l}\text { Rule-based } \\
\text { approach }\end{array}$ \\
\hline Resources & $\begin{array}{l}\text { Freeware software tool with } \\
\text { little pedagogic support }\end{array}$ & $\begin{array}{l}\text { Closed-source/access } \\
\text { online platform with } \\
\text { extensive pedagogic } \\
\text { support }\end{array}$ & $\begin{array}{l}\text { Now depreciated. } \\
\text { Closed- } \\
\text { source/access } \\
\text { online platform } \\
\text { with limited } \\
\text { pedagogic support }\end{array}$ & $\begin{array}{l}\text { Open-source } \\
\text { platform with } \\
\text { developing } \\
\text { pedagogic } \\
\text { support and } \\
\text { customization }\end{array}$ \\
\hline
\end{tabular}

The tools described above target the same functional moves in texts in order to provide feedback to students to improve their writing. However, the tools described take two broad approaches to this analysis, which share some benefits and drawbacks, as summarized below.

Machine learning approaches have been applied in Mover and RWT. While Mover has been used in small-scale contexts both to analyze student writing and to investigate its potential for supporting student learning of rhetorical moves, its evaluation remains small scale. In addition, the models used are trained on a small dataset from a specific discipline (100 IT research abstracts), and thus its applicability to a wider dataset - albeit one that should instantiate many of the same properties - is unclear. However, RWT, building on this approach, has been successfully developed for multiple disciplines by training on labelled corpora for those disciplines. In both cases, the annotation process involved labelling all sentences, and then the implementation of those models into feedback by labelling the sentences with the move that received the highest probability, indicating that the sentence instantiated that move. While these approaches could be adjusted and have certain benefits, the approach differs from a rule-based approach in that sentences that might exhibit low certainty for instantiating any move will 
still receive an annotation. Thus, there are pedagogic implications to the approach and implementation, insofar as there may be occasions on which learning would be best supported by flagging that moves are not instantiated in a sentences.

The rule-based approaches described above implement instantiations of a conceptual model of rhetorical moves into a parser. By not relying on a large corpus of human-annotated data, which may include rhetorical moves outside the scope of the model, this approach increases the potential for false negatives or poor recall. On the other hand, the automated annotations maintain high fidelity to the theoretical construct, resulting in good intrinsic precision. At the same time, the rule-based approach has the advantage of being transparent to students. It defines conceptually the scope of the patterns that convey the rhetorical meaning, and thus students understand the automated annotations and can make use of a great diversity of instantiations of the rhetorical moves. This system has a technical limitation insofar as the syntactic parsing relies on a relatively slow external server, which may make the analyses of longer documents somewhat time-consuming.

\subsubsection{Overview of Rhetorical Coding Schemes}

The rhetorical analysis tools described above are grounded in the same literature, often framed in slightly different ways. In this paper, we focus on the rhetorical elements of introductions and abstracts because these are the sections that mainly share moves or steps across the tools. The annotated elements in each tool are indicated in Table 2. Whereas AWA/AcaWriter annotates rhetorically salient sentences, Mover and RWT annotate all of the sentences.

Table 2. Coding Schemes of Tools That Identify Rhetorical Structures

\begin{tabular}{|c|c|c|}
\hline Mover & RWT & AWA/AcaWriter \\
\hline $\begin{array}{l}\text { Modified CARS model } \\
\text { with three main moves } \\
\text { and further steps: } \\
\text { 1. Establish a territory. } \\
\text { - Claim centrality. } \\
\text { - Generalize topics. } \\
\text { - Review previous } \\
\text { research. } \\
\text { 2. Establish a niche. } \\
\text { - Counter claim. } \\
\text { - Indicate a gap. } \\
\text { - Raise questions. } \\
\text { - Continue a tradition. } \\
\text { 3. Occupy the niche. } \\
\text { - Outline purpose. } \\
\text { - Announce research. } \\
\text { - Announce findings. } \\
\text { - Evaluate research. } \\
\text { - Indicate RA } \\
\text { structure. }\end{array}$ & $\begin{array}{l}\text { Modified CARS model with } 3 \text { moves, } 17 \text { steps: } \\
\text { Move 1. Establish a territory: } \\
\text { 1. Claim centrality. } \\
\text { 2. Make topic generalizations. } \\
\text { 3. Review previous research. } \\
\text { Move 2. Identify a niche: } \\
\text { 4. Indicate a gap. } \\
\text { 5. Highlight a problem. } \\
\text { 6. Raise general questions. } \\
\text { 7. Propose general hypotheses. } \\
\text { 8. Present a justification. } \\
\text { Move 3. Address the niche: } \\
\text { 9. Introduce present research descriptively. } \\
\text { 10. Introduce present research purposefully. } \\
\text { 11. Present research questions. } \\
\text { 12. Present research hypotheses. } \\
\text { 13. Clarify definitions. } \\
\text { 14. Summarize methods. } \\
\text { 15. Announce principal outcomes. } \\
\text { 16. State the value of the present research. } \\
\text { 17. Outline the structure of the paper. }\end{array}$ & $\begin{array}{l}\text { Rhetorically salient sentence } \\
\text { types related to CARS steps: } \\
\text { - Summarizing } \\
\text { - Background knowledge } \\
\text { - Contrasting ideas } \\
\text { - Novelty } \\
\text { - Significance } \\
\text { - Surprise } \\
\text { - Open question } \\
\text { - Generalizing } \\
\text { Mapped to CARS for the } \\
\text { Research Introductions/Abstracts } \\
\text { version of Acawriter: } \\
\text { Move } 1 \text { : } \\
\text { - Background knowledge } \\
\text { - Emphasis } \\
\text { Move } 2 \text { : } \\
\text { - Contrasting ideas } \\
\text { - Open question } \\
\text { Move } 3 \text { : } \\
\text { - Novelty } \\
\text { - Summary }\end{array}$ \\
\hline
\end{tabular}

\subsection{Open Corpora}

A key challenge in comparing tools and sharing their outputs for both research and pedagogic purposes (e.g., validation and exemplification) is the lack of shared datasets. Across the tools described, there is no shared public dataset for testing or training purposes. Nor does such a dataset exist for comparative purposes, that is, demonstrating the application of each tool to a shared corpus. It is this challenge that the present work addresses.

To provide such an annotated corpus, we sought to obtain corpora that align with the genres of writing that the tools were developed for, that is, scholarly academic communication. Thus, we obtained three sample open-access corpora for analysis across tools:

1. The British Academic Written English (BAWE) corpus (Nesi, Gardner, Thompson, and Wickens, 2004), "contains just under 3000 good-standard student assignments (6,506,995 words). Holdings are fairly evenly distributed across four broad disciplinary areas (Arts and Humanities, Social Sciences, Life Sciences and Physical Sciences) and across four levels of study (undergraduate and coursework masters level). Thirty main disciplines are represented." (Nesi et al., 
2004). These texts are typically shorter written assignments that were submitted by students to develop the corpus (for a small fee), under a Creative Commons Attribution-NonCommercial-ShareAlike 3.0 Unported License.

2. The Elsevier Open Access Science Technology and Mathematics (OA-STM) corpus (Elsevier Labs, 2015) packages a set of open-access CC-By (Elsevier published) articles within 10 domains. "The domains are agriculture, astronomy, biology, chemistry, computer science, earth science, engineering, materials science, math, and medicine. Currently we provide 11 articles in each of the 10 domains." (Elsevier Labs, 2015).

3. A subset of the Pubmed Central corpus comprises biomedical and life sciences literature under an open licence (PMC, n.d.).

Each of these corpora contains examples of authentic scholarly writing. The content of the writing differs within and between these corpora based on discipline, text section, and text level. In particular, we note that student writing (in the BAWE) is intended to approximate scholarly academic writing but of course has a number of distinctive features, including a shorter length. The texts in that corpus are of a "high standard," and it is one of the few openly available corpora of student writing. Our analysis focuses on the structural aspects of writing using rhetorical moves; as such, we expect these features to be instantiated across the target corpora.

\section{Applying Tools to a Shared Dataset}

\subsection{Data Structure and Access}

The database consists of six tables: (1) corpus, describing the three different corpora, including their licences; (2) document, describing the papers and their disciplines per corpus; (3) sentence, detailing the sentence, and the section (e.g., introduction, conclusion) in which it occurs per document; (4) annotation, describing the different labels for the annotations, that is, the rhetorical moves/steps, per tool; (5) sentence annotation, providing the annotations for every sentence per tool, including the probability value for the annotation (only for RWT); (6) tool, describing the three different tools that have been used to annotate the sentences in the corpora. An overview of the database structure can be found in Figure 8.

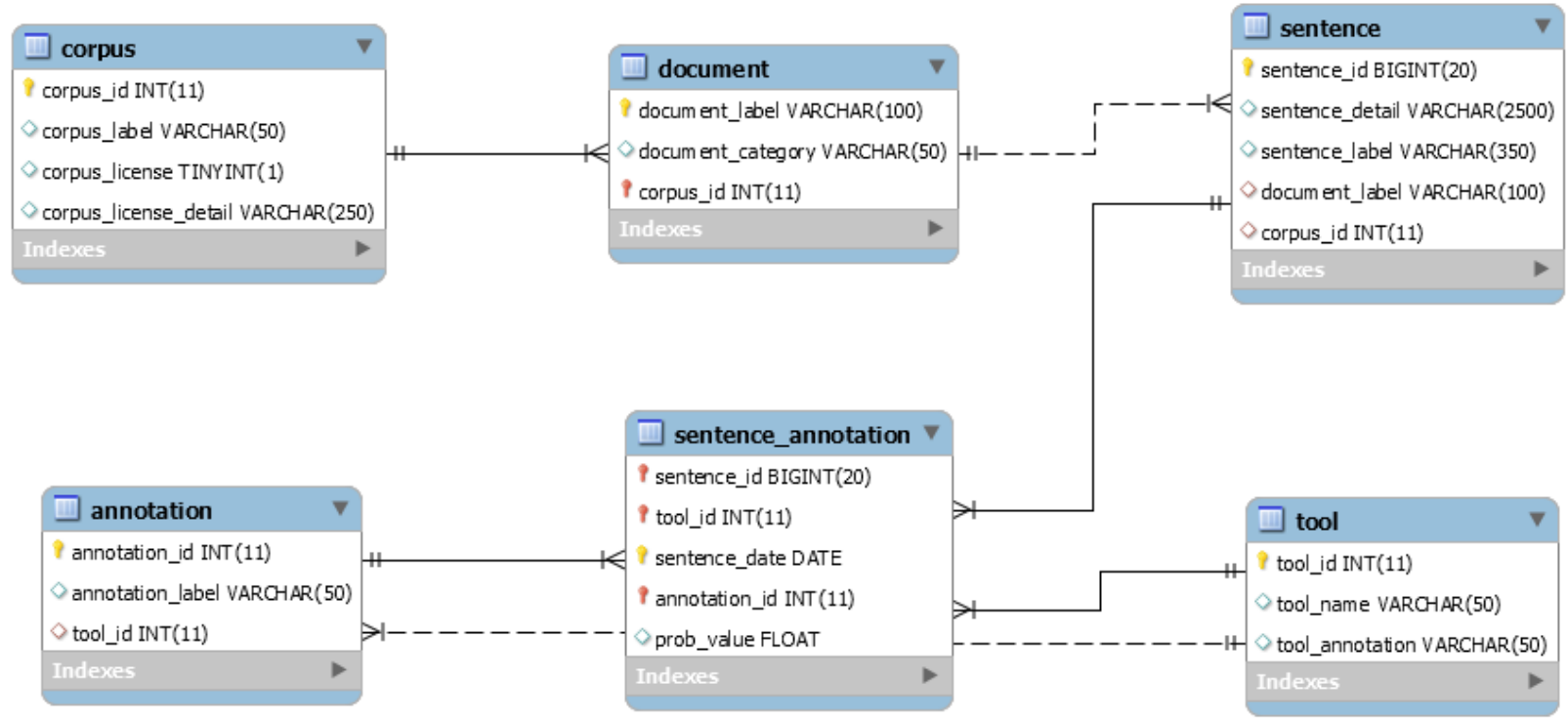

Figure 8. Enhanced entity relationship database diagram

The database can be accessed (Knight, Abel, et al., (2020)). A number of scripts exist at https://github.com/uts-cic/corpusanalysis/ that provide R and Python interfaces to the database, basic transformation, and some sample analyses. To illustrate the use of the open database, several of these analyses were conducted, with results as indicated below, showing the number of moves/steps in the database in general, and per corpus, section, and discipline, as well as the associations between annotations across tools.

\subsection{Corpus Description and Illustrative Uses}

\subsubsection{Corpus Description}

The available database consists of 5,186 text documents, spread over the three corpora: OASTM, PMC, and BAWE. In total, all documents contain 820,305 sentences. On average there are $158(S . D .=156)$ sentences per document. The descriptive statistics per corpus can be found in Table 3. This table shows that the BAWE documents are the shortest in terms of the 
number of sentences per document, and the OASTM corpus has the fewest documents. Table 4 shows the average number of sentences per document section for each corpus. The BAWE corpus consists of documents that mainly include a discussion, a short introduction, and a conclusion. The OASTM and PMC documents show especially longer methods sections.

Table 3: Descriptive Statistics for Available Corpora

\begin{tabular}{lllll}
\hline Corpus & $\begin{array}{l}\text { Number of } \\
\text { documents }\end{array}$ & $\begin{array}{l}\text { Number of } \\
\text { sentences }\end{array}$ & $\begin{array}{l}\text { Mean sentences } \\
\text { per document }\end{array}$ & $\begin{array}{l}\text { S.D. sentences } \\
\text { per document }\end{array}$ \\
\hline BAWE & 2,761 & 270,815 & 98 & 62 \\
\hline OASTM & 110 & 30,829 & 280 & 190 \\
\hline PMC & 2,315 & 518,661 & 224 & 198 \\
\hline
\end{tabular}

Table 4: Average Number of Sentences per Document Section per Corpus

\begin{tabular}{lllllll}
\hline Corpus & Abstract & Introduction & Background & Method & Discussion & Conclusion \\
\hline BAWE & 0 & 4.5 & 0 & 0 & 90.3 & 4.0 \\
\hline OASTM & 8.3 & 26.1 & 12.6 & 210 & 48.8 & 9.7 \\
\hline PMC & 17.9 & 24.3 & 14.5 & 138 & 73.6 & 7.0 \\
\hline
\end{tabular}

\subsubsection{Corpus Annotation}

AntMover, AWA, and AcaWriter each processed all of the sentences in the corpus, with RWT processing a subset of this corpus (all of the OASTM and BAWE documents, and 1,104 of the PMC documents).

Depending on the tool, a sentence can be annotated with zero, one, or more rhetorical categories, resulting in more than two million annotations. For the RWT tool, each rhetorical move and step is given a probability value. Therefore, in the analyses, sentences may be annotated by assigning the move with the highest probability.

Based on the literature introduced earlier, we focus specifically on sentences in the introduction, background, and abstract sections. An overview of the annotations per tool for every corpus can be found in Figure 9, which shows the number and type of annotations by rhetorical move/step and corpus for each tool as a proportion of input sentences for that tool.

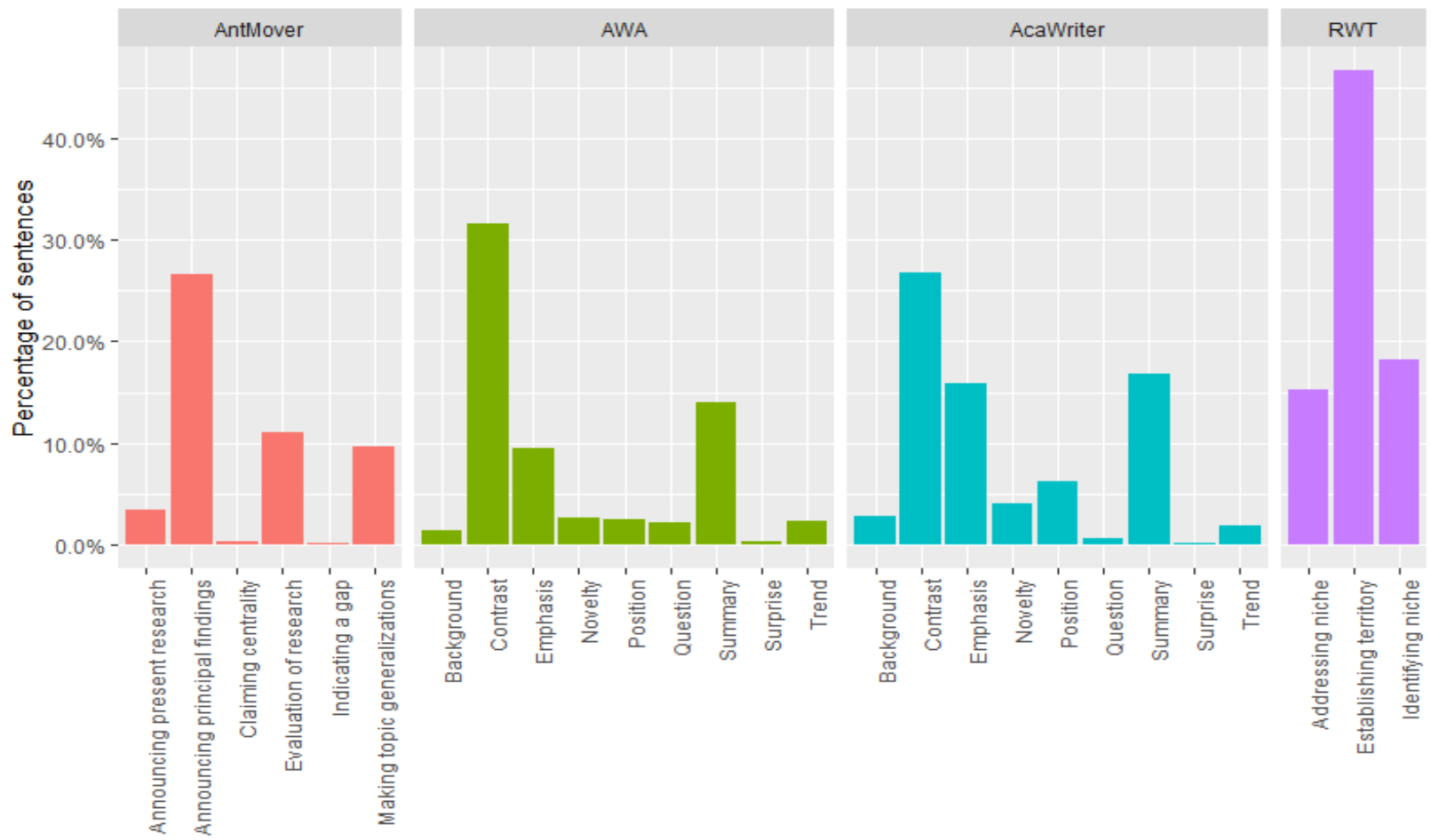

Amasabon bese

Figure 9. Percentage of abstract, background, and introduction sentences annotated with a specific rhetorical move per tool 


\subsubsection{Comparisons of Annotations over Tools}

While these annotated corpora provide potential for computational analyses, we also note their potential in augmenting human coding to support both further computational analysis and pedagogic ends. For example, we foresee potential in analyzing associations between moves/steps across the tools, and in comparisons here particularly between versions of the same approach (AWA and AcaWriter), as well as across approaches. Here, we highlight a set of manual analyses, indicating how the annotations - and (dis)agreement over tools - can be used both for tool development and for pedagogic purposes (e.g., providing exemplar sentences).

\subsubsection{Annotation Approaches: Rules, Machine Learning, and Underlying Technologies}

A particular focus of this comparison was in understanding how technical differences in the tool implementation, including the annotation approach (rule-based versus machine learning), and underlying technologies relate to the annotation outputs and their use. Such comparison of outputs from differing technical implementations can complement gold-standard human annotation.

For example, as explained above, the AcaWriter parser is the adaptation of AWA to a new open-source tool set. Whereas in AWA both general syntactic analysis and concept-matching rule implementation are carried out by XIP, in AcaWriter (and its underlying Athanor parser), syntactic analysis is carried out by the Stanford CoreNLP Parser and the implementation of concept-matching rules by Athanor. This change in tools results in differences in output. First, XIP is a rule-based syntactic parser, and thus it could be adapted to better serve the concept-matching tools, contrary to the Stanford CoreNLP Parser, which is a black box. Further, the two syntactic analyses may be different at all levels (segmentation, part-of-speech tagging, lexical features, etc.), which may affect the output. The adaptation of the concept-matching rules for Athanor was not straightforward, and we were not able to test it on a large dataset. A detailed comparison of AWA and AcaWriter output of the present dataset could lead to a considerable improvement of Athanor quality. The transfer of technologies is frequent in educational technology, and this transfer can have sizeable impact

A preliminary study (Cotos \& Sándor, 2018) has been reported, conducted to compare the move/step and concept-matching analyses underlying RWT and AWA/AcaWriter, respectively. The concept-matching framework was applied first on introduction move/step definitions and prototypical example sentences taken from the RWT annotation guidelines (see an example in Figure 10) and next on a subset of the RWT development corpus (see earlier discussion), where moves and steps were annotated by a team of experts (Cotos et al., 2015). In the first case, most step definitions and many example sentences realized a concept pattern encoded into AWA/AcaWriter; however, there was no one-to-one correspondence between steps and concept-matching categories. The step definitions that do not realize any concept pattern (see an example in Figure 11) may open the way for defining further concept-matching categories.

\begin{tabular}{|c|c|c|}
\hline $\begin{array}{l}\text { RWT: Move } 2 \text { Step } 2 \\
\text { Highlighting a } \\
\text { problem }\end{array}$ & & AcaWriter label \\
\hline definition & $\begin{array}{l}\text { Specifies problems/challenges in the } \\
\text { targeted research agenda or domain of } \\
\text { practice that require attention and/or } \\
\text { improvement }\end{array}$ & $\begin{array}{l}\text { N C Specifies problems/challenges in the targeted } \\
\text { research agenda or domain of practice that require attention } \\
\text { and/or improvement. }\end{array}$ \\
\hline example sentence & $\begin{array}{l}\text { The one limitation to these findings } \\
\text { regarding narrow-row soybean is that all } \\
\text { the studies were done with non- } \\
\text { glyphosate-resistant cultivars. }\end{array}$ & $\begin{array}{l}\text { S C The one limitation to these findings regarding } \\
\text { narrow-row soybean is that all the studies were done with } \\
\text { non-glyphosate-resistant cultivars. }\end{array}$ \\
\hline
\end{tabular}

Figure 10. Example of AcaWriter annotation on RWT step definition and example sentence

\begin{tabular}{|c|l|l|}
$\begin{array}{c}\text { RWT: Move 2. Step 4 } \\
\text { Proposing general } \\
\text { hypotheses }\end{array}$ & AcaWriter label \\
\hline definition & $\begin{array}{l}\text { Puts forth general hypotheses about } \\
\text { possible future findings or implications } \\
\text { based on the existing body of knowledge } \\
\text { and/or based on the knowledge territory } \\
\text { and/or based on the identified gap or } \\
\text { problem }\end{array}$ & - \\
\hline example sentence & $\begin{array}{l}\text { The one limitation to these findings } \\
\text { regarding narrow-row soybean is that all } \\
\text { the studies were done with non- } \\
\text { glyphosate-resistant cultivars. }\end{array}$ & \\
\hline
\end{tabular}

Figure 11. Example of no AWA annotation on RWT step definition and example sentence Such examples could lead to modelling new rhetorically salient sentence types 
In a second study (also presented in Cotos \& Sándor, 2018), manual move/step annotations and automated conceptmatching annotations were overlaid on the same corpus. It was found that AWA concept patterns are used transversally across RWT steps as context-free devices of rhetorical salience. In this study, it was observed that particular concept patterns sometimes strongly characterize the realization of particular RWT steps. For example, Contrasting Ideas is a far more frequent AWA label in "indicating a gap," "highlighting a problem," and "raising general questions" than in any other rhetorical steps. This is expected, since all three steps convey research problems; that is, the author presents diverse ideas of the state of the art. Another example is that the EMPHASIS, SURPRISE, and NOVELTY AWA labels are found to be more frequent in the "indicating a gap" step than in other steps. This is less expected, since at first sight there does not seem to be any specific reason to use these devices more often for "indicating a gap" than for "highlighting a problem" or "realizing general questions." Investigating the reasons for this correlation is an interesting question.

Thus, we conclude that the two analytic frameworks - and shared annotated corpora such as those provided here - may be mutually informative for each other: move analysis can enrich the inventory of concepts and concept patterns, and conceptbased analysis, in turn, can provide a fine-grained representation of functional language used to accomplish communicative goals.

\section{Conclusion and Discussion}

The rhetorical structure of writing is an important discourse construct characterized by specific linguistic features. Students must learn to use these linguistic features in their academic writing. As a result, a variety of tools have been developed to analyze these rhetorical moves, and in some cases to provide feedback to students. However, these tools have typically been developed independently and are not based on shared datasets or technologies. Thus, in this paper, we have described tools designed to annotate rhetorical structures in texts, alongside an open dataset of annotated moves. A key benefit of its open nature - including annotations from tools that are not openly available — is that additional analyses, both automated and human, may be appended to the dataset. Such analyses could include measures of cohesion, sequence analysis, and analysis of the quality of the writing, as well as of course the relationships among these features. We also point to the urgent need in learning analytics for shared open datasets, including corpora of student writing that include quality indicators (i.e., grade) across a range of qualities (building on the "high-grade" BAWE corpus).

The dataset also gives an example insight into how changes to an underlying technology may-independent of theory and purpose - impact results, through the comparison of the AWA/AcaWriter tools. In addition, it provides useful insight into the ways that rhetorical structures are operationalized across tools, including comparison of rule-based versus machine learningbased approaches, or labelling all sentences (RWT and Mover) or salient sentences only (AWA/AcaWriter). This aspect has clear pedagogic implications; texts in which all sentences are labelled compared to those in which only some are labelled are likely to require rather different models of student feedback on both the presence and absence of key features. The dataset provides a starting point for work on such feedback models, and the role of annotation as a form of feedback, as well as providing a labelled dataset from an established published corpus that itself can be used to provide exemplar sentences as a form of feedback.

\section{Declaration of Conflicting Interest}

All review processes and editorial decisions have been made independent of, and blinded from, the first author-who is a CoEditor-in-Chief of the Journal - at all stages of the manuscript submission. The authors declared no potential conflicts of interest with respect to the research, authorship, and/or publication of this article.

\section{Funding}

The authors declared no financial support for the research, authorship, and/or publication of this article.

\section{Acknowledgements}

The authors gratefully acknowledge support from the University of Technology Sydney, Deputy Vice Chancellor (Education and Students), for this work and for the development of the AWA tools. We would also like to acknowledge Claude Roux, researcher at Naver Labs Europe, who developed Athanor, and Jean-Pierre Chanod, area manager at Naver Labs Europe, for promoting UTS/Xerox/Naver collaboration. Rianne Conijn would like to acknowledge the support of Australia Award (6381_2018) Endeavour Fellowship provided to support an international visit to the Connected Intelligence Centre at UTS. 


\section{References}

Aït-Mokhtar, S., Chanod, J.-P., \& Roux, C. (2002). Robustness beyond shallowness: Incremental deep parsing. Natural Language Engineering, 8(2-3), 121-144. https://dx.doi.org/10.1017/S1351324902002887

Allen, L. K., Jacovina, M. E., \& McNamara, D. S. (2016). Computer-based writing instruction. In C. A. MacArthur, S. Graham, \& J. Fitzgerald (Eds.), Handbook of Writing Research (pp. 316-329). New York, NY: Guilford Press. Retrieved from https://eric.ed.gov/?id=ED586512

Anthony, L. (1999). Writing research article introductions in software engineering: How accurate is a standard model? IEEE Transactions on Professional Communication, 42(1), 38-46. https://dx.doi.org/10.1109/47.749366

Anthony, L., \& Lashkia, G. V. (2003). Mover: A machine learning tool to assist in the reading and writing of technical papers. IEEE Transactions on Professional Communication, 46(3), 185-193. https://dx.doi.org/10.1109/TPC.2003.816789

Buckingham Shum, S., Knight, S., McNamara, D., Allen, L. K., Betik, D., \& Crossley, S. (2016). Critical perspectives on writing analytics. In Proceedings of the 6th International Conference on Learning Analytics and Knowledge (LAK '16), 25-29 April 2016, Edinburgh, UK (pp. 481-483). New York, NY: ACM. https://dx.doi.org/10.1145/2883851.2883854

Buckingham Shum, S., Sándor, Á., Goldsmith, R., Wang, X., Bass, R., \& McWilliams, M. (2016). Reflecting on reflective writing analytics: Assessment challenges and iterative evaluation of a prototype tool. Proceedings of the 6th International Conference on Learning Analytics \& Knowledge, 25-29 April 2016, Edinburgh, UK (pp. 213-222). New York, NY: ACM. https://dx.doi.org/10.1145/2883851.2883955

Burstein, J., Chodorow, M., \& Leacock, C. (2003). Criterion ${ }^{\mathrm{SM}}$ online essay evaluation: An application for automated evaluation of student essays. In J. Riedl \& R. W. Hill Jr. (Eds.), Proceedings of the Fifteenth Conference on Innovative Applications of Artificial Intelligence (IAAI 2003), 12-14 August 2003, Acapulco, Mexico (pp. 3-10). Retrieved from https://dblp.org/db/conf/iaai/iaai2003.html

Cai, (L.) J. (2016). An exploratory study on an integrated genre-based approach for the instruction of academic lexical phrases. Journal of English for Academic Purposes, 24, 58-74. https://dx.doi.org/10.1016/J.JEAP.2016.09.002

Chang, C.-F., \& Kuo, C.-H. (2011). A corpus-based approach to online materials development for writing research articles. English for Specific Purposes, 30(3), 222-234. https://dx.doi.org/10.1016/j.esp.2011.04.001

Cope, B., \& Kalantzis, M. (1993). Introduction: How a genre approach to literacy can transform the way writing is taught. In B. Cope \& M. Kalantzis (Eds.), The powers of literacy: A genre approach to teaching writing (pp. 1-21). London, UK: Taylor \& Francis. Retrieved from https://www.taylorfrancis.com/books/9780203149812/chapters/10.4324/9780203149812-9

Cotos, E. (2011). Potential of automated writing evaluation feedback. CALICO Journal, 28(2), 420-459. https://dx.doi.org/10.11139/cj.28.2.420-459

Cotos, E. (2014). Enhancing writing pedagogy with learner corpus data. ReCALL, 26(2), 202-224. https://dx.doi.org/10.1017/S0958344014000019

Cotos, E. (2016). Computer-assisted research writing in the disciplines. In S. A. Crossley \& D. S. McNamara (Eds.), Adaptive educational technologies for literacy instruction (pp. 225-242). London, UK: Taylor \& Francis. Retrieved from https://www.taylorfrancis.com/books/9781315647500/chapters/10.4324/9781315647500-15

Cotos, E. (2018). Move analysis. In C. A. Chapelle (Ed.), The encyclopedia of applied linguistics (pp. 1-8). Oxford, UK: John Wiley \& Sons. https://dx.doi.org/10.1002/9781405198431.wbeal1485

Cotos, E., Huffman, S., \& Link, S. (2015). Furthering and applying move/step constructs: Technology-driven marshalling of Swalesian genre theory for EAP pedagogy. Journal of English for Academic Purposes, 19, 52-72. https://dx.doi.org/10.1016/j.jeap.2015.05.004

Cotos, E., Huffman, S., \& Link, S. (2017). A move/step model for methods sections: Demonstrating rigour and credibility. English for Specific Purposes, 46, 90-106. https://dx.doi.org/10.1016/j.esp.2017.01.001

Cotos, E., Huffman, S., \& Link, S. (2020). Understanding graduate writers' interaction with and impact of the Research Writing Tutor during revision. Journal of Writing Research, 12(1), 187-232. https://dx.doi.org/10.17239/jowr2020.12.01.07

Cotos, E., Link, S., \& Huffman, S. R. (2016). Studying disciplinary corpora to teach the craft of discussion. Writing and Pedagogy, 87(1), 33-64. https://dx.doi.org/10.1558/wap.v8i1.27661

Cotos, E., Link, S., \& Huffman, S. (2017). Effects of DDL technology on genre learning. Language Learning \& Technology, 21(3), 104-130. https://dx.doi.org/10125/44623

Cotos, E., \& Pendar, N. (2016). Discourse classification into rhetorical functions for AWE feedback. Calico Journal, 33(1), 92-116. https://dx.doi.org/10.1558/cj.v33i1.27047

Cotos, E., \& Sándor, Á. (2018). Testing an integrated method for the automated analysis of rhetorical intent in academic genres. Paper presented at AAAL Conference 2018, 24-27 March 2018, Chicago, IL, USA. 
De Liddo, A., Sándor, Á., \& Buckingham Shum, S. (2012). Contested collective intelligence: Rationale, technologies, and a human-machine annotation study. Computer Supported Cooperative Work (CSCW), 21(4), 417-448.

https://dx.doi.org/10.1007/s10606-011-9155-x

Elsevier Labs. (2015). OA STM Corpus. Elsevier Labs Github. Retrieved from http://elsevierlabs.github.io/OA-STMCorpus/

Flower, L. S., \& Hayes, J. R. (1977). Problem-solving strategies and the writing process. College English, 39(4), 449-461. https://dx.doi.org/10.2307/375768

Gibson, A., Aitken, A., Sándor, Á., Buckingham Shum, S., Tsingos-Lucas, C., Knight, S., ..., Jarvis, W. (2017). Reflective writing analytics for actionable feedback in authentic assessment. In Proceedings of the 7th International Conference on Learning Analytics \& Knowledge (LAK '17), 13-17 March 2017, Vancouver, BC, Canada (pp. 153-162). New York, NY: ACM. https://dx.doi.org/10.1145/3027385.3027436

Hyland, K. (2007). Genre pedagogy: Language, literacy and L2 writing instruction. Journal of Second Language Writing, 16(3), 148-164. https://dx.doi.org/10.1016/j.jslw.2007.07.005

Knight, S., Abel, S., Shibani, A., Yoong Kuan, G., Conijn, R., Gibson, A., ..., Buckingham Shum, S. (2020). Are you being rhetorical? An open dataset of machine annotated rhetorical moves. Stash. https://dx.doi.org/10.26195/5f336ead59a43

Knight, S., Allen, L. K., Gibson, A., McNamara, D., \& Buckingham Shum, S. (2017). Writing analytics literacy—Bridging from research to practice. In Proceedings of the 7th International Conference on Learning Analytics \& Knowledge (LAK '17), 13-17 March 2017, Vancouver, BC, Canada (pp. 496-497). New York, NY: ACM. https://dx.doi.org/10.1145/3027385.3029425

Knight, S., Buckingham Shum, S., Ryan, P., Sándor, Á., \& Wang, X. (2018). Academic writing analytics for civil law: Participatory design through academic and student engagement. International Journal of Artificial Intelligence in Education, 28(1), 1-28. https://dx.doi.org/10.1007/s40593-016-0121-0

Knight, S., Shibani, A., Abel, S., Gibson, A., Ryan, P., Sutton, N., ..., Buckingham Shum, S. (2020). AcaWriter: A learning analytics tool for formative feedback on academic writing. Journal of Writing Research, 12(1), 141-186. https://dx.doi.org/10.17239/jowr-2020.12.01.06

Kuteeva, M., \& Negretti, R. (2016). Graduate students' genre knowledge and perceived disciplinary practices: Creating a research space across disciplines. English for Specific Purposes, 41, 36-49. https://dx.doi.org/10.1016/J.ESP.2015.08.004

Liakata, M., Saha, S., Dobnik, S., Batchelor, C., \& Rebholz-Schuhmann, D. (2012). Automatic recognition of conceptualization zones in scientific articles and two life science applications. Bioinformatics, 28(7), 991-1000. https://dx.doi.org/10.1093/bioinformatics/bts071

Lisacek, F., Chichester, C., Kaplan, A., \& Sándor, Á. (2005). Discovering paradigm shift patterns in biomedical abstracts: Application to neurodegenerative diseases. In Proceedings of the First International Symposium on Semantic Mining in Biomedicine (SMBM), 11-13 April 2005, Cambridge, UK (pp. 41-50). Retrieved from https://www.researchgate.net/publication/228635443_Discovering_Paradigm_Shift_Patterns_in_Biomedical_Abstract S_Application_to_Neurodegenerative_Diseases

Mann, W. C., \& Thompson, S. A. (1987). Rhetorical structure theory: Description and construction of text structures. In G. Kempen (Ed.), Natural language generation (Vol. 135) (pp. 85-95). Dordrecht, The Netherlands: Springer. https://dx.doi.org/10.1007/978-94-009-3645-4_7

McDonald, J., Moskal, A. C. M., Gunn, C., \& Donald, C. (2018). Text analytic tools to illuminate student learning. In J. M. Lodge, J. C. Horvath, \& L. Corrin (Eds.), Learning analytics in the classroom: Translating learning analytics for teachers. London, UK: Taylor \& Francis. https://dx.doi.org/10.4324/9781351113038-11

Mizumoto, A., Hamatani, S., \& Imao, Y. (2017). Applying the bundle-move connection approach to the development of an online writing support tool for research articles. Language Learning, 67(4), 885-921. https://dx.doi.org/10.1111/lang. 12250

National Commission On Writing. (2003). Report of the National Commission on writing in America's schools and colleges: The neglected " $R$," the need for a writing revolution. The College Board. Retrieved from https://archive.nwp.org/cs/public/print/resource/2523

Nesi, H., Gardner, S., Thompson, P., \& Wickens, P. (2004). British academic written English corpus. Oxford Text Archive. Oxford, UK: University of Oxford. Retrieved from http://purl.ox.ac.uk/ota/2539

PMC. (n.d.). Open Access Subset. Retrieved from https://www.ncbi.nlm.nih.gov/pmc/tools/openftlist/

Sándor, Á. (2007). Modeling metadiscourse conveying the author's rhetorical strategy in biomedical research abstracts. Revue française de linguistique appliquée, 12(2), 97-108. https://dx.doi.org/10.3917/rfla.122.0097

Sándor, Á., Kaplan, A., \& Rondeau, G. (2006). Discourse and citation analysis with concept-matching. In Proceedings of the International Symposium: Discourse and Document (ISDD), 15-16 June 2006, Caen, France (pp. 147-152). Retrieved from https://www.researchgate.net/publication/240828357_Discourse_and_citation_analysis_with_concept-matching 
Sándor, Á., \& Vorndran, A. (2009). Detecting key sentences for automatic assistance in peer reviewing research articles in educational sciences. In Proceedings of the 2009 Workshop on Text and Citation Analysis for Scholarly Digital Libraries, 7 August 2009, Singapore (pp. 36-44). Stroudsburg, PA, USA: Association for Computational Linguistics. https://dx.doi.org/10.3115/1699750.1699757

Scardamalia, M., \& Bereiter, C. (1987). Knowledge telling and knowledge transforming in written composition. Advances in Applied Psycholinguistics, 2, 142-175.

Shermis, M. D., \& Burstein, J. (Eds.). (2013). Handbook of automated essay evaluation: Current applications and new directions. London, UK: Routledge/Taylor \& Francis. Retrieved from https://psycnet.apa.org/record/2013-15323-000

Shibani, A. (2018a). AWA-Tutor: A platform to ground automated writing feedback in robust learning design. In S. Buckingham Shum, R. Ferguson, A. Merceron, \& X. Ochoa (Eds.), Companion Proceedings of the 8th International Learning Analytics and Knowledge Conference (LAK '18), 5-9 March 2018, Sydney, Australia. Society for Learning Analytics Research (SoLAR). Retrieved from http://bit.ly/lak18-companion-proceedings

Shibani, A. (2018b). Developing a learning analytics intervention design and tool for writing instruction. In S. Buckingham Shum, R. Ferguson, A. Merceron, \& X. Ochoa (Eds.), Companion Proceedings of the 8th International Conference on Learning Analytics \& Knowledge (LAK '18), 5-9 March 2018, Sydney, Australia. Society for Learning Analytics Research (SoLAR). Retrieved from http://bit.ly/lak18-companion-proceedings

Shibani, A., Abel, S., Gibson, A., \& Knight, S. (2018). Turning the TAP on writing analytics. In S. Buckingham Shum, R. Ferguson, A. Merceron, \& X. Ochoa (Eds.), Companion Proceedings of the 8th International Conference on Learning Analytics \& Knowledge (LAK '18), 5-9 March 2018, Sydney, Australia. Society for Learning Analytics Research (SoLAR). Retrieved from http://bit.ly/lak18-companion-proceedings

Shibani, A., Knight, S., \& Buckingham Shum, S. (2019). Contextualizable learning analytics design: A generic model and writing analytics evaluations. Proceedings of the 9th International Conference on Learning Analytics and Knowledge (LAK '19), 4-8 March 2018, Tempe, AZ, USA (pp. 210-219). New York, NY: ACM. https://dx.doi.org/10.1145/3303772.3303785

Shibani, A., Knight, S., \& Buckingham Shum, S. (2020). Educator perspectives on learning analytics in classroom practice. Internet and Higher Education, 46, 100730. https://dx.doi.org/10.1016/j.iheduc.2020.100730

Shibani, A., Knight, S., Buckingham Shum, S., \& Ryan, P. (2017). Design and implementation of a pedagogic intervention using writing analytics. In W. Chen, J.-C. Yang, A. F. Mohd Ayub, S. L. Wong, \& A. Mitrovic (Eds.), Proceedings of the 25th International Conference on Computers in Education, 4-8 December 2017, Christchurch, New Zealand (pp. 306-315). Asia-Pacific Society for Computers in Education. Retrieved from https://www.apsce.net/icce/icce2017/140.115.135.84/icce/icce2017/proceedings_main.html

Simsek, D., Sándor, Á., Buckingham Shum, S., Ferguson, R., De Liddo, A., \& Whitelock, D. (2015). Correlations between automated rhetorical analysis and tutors' grades on student essays. Proceedings of the 5th International Conference on Learning Analytics and Knowledge (LAK '15), 16-20 March 2015, Poughkeepsie, NY, USA (pp. 355-359). New York, NY: ACM. https://dx.doi.org/10.1145/2723576.2723603

Swales, J. (1981). Aspects of article introductions (Aston ESP reports No. 1). Birmingham, UK: The University of Aston in Birmingham.

Swales, J. (1990). Genre analysis: English in academic and research settings. Cambridge, UK: Cambridge University Press.

Teufel, S., \& Moens, M. (2002). Summarizing scientific articles: Experiments with relevance and rhetorical status. Computational Linguistics, 28(4), 409-445. https://dx.doi.org/10.1162/089120102762671936

Warschauer, M., \& Grimes, D. (2008). Automated writing assessment in the classroom. Pedagogies: An International Journal, 3(1), 22-36. https://dx.doi.org/10.1080/15544800701771580

Wingate, U. (2012). Using Academic Literacies and genre-based models for academic writing instruction: A "literacy" journey. Journal of English for Academic Purposes, 11(1), 26-37. https://dx.doi.org/10.1016/j.jeap.2011.11.006

Yan, D., Rupp, A. A., \& Foltz, P. W. (Eds.). (2020). Handbook of automated scoring: Theory into practice. London, UK: Chapman and Hall/CRC. Retrieved from https://www.routledge.com/Handbook-of-Automated-Scoring-Theory-intoPractice/Yan-Rupp-Foltz/p/book/9781138578272 